\title{
Sustainability Reporting out of a Prisoner's Dilemma
}

\author{
Thomas Kaspereit* \\ University of Oldenburg, Accounting and Corporate Governance \\ Ammerländer Heerstr. 114-118, 26111 Oldenburg
}

\begin{abstract}
Listed firms increasingly strive for a sustainable appearance, which has made sustainability reporting very popular in recent years. This would be completely rational if sustainability reporting could enhance shareholder value. This paper investigates from a theoretical perspective which conditions are sufficient for the individual and collective rationality of sustainability reporting. The analysis leads to the conclusion that, due to the competition between firms, sustainability reporting generates a separation equilibrium as long as the reporting costs are proportional to the reported level and the marginal costs of reporting differ with the true level of sustainability. Although it might be preferable, a pooling equilibrium with no sustainability reporting cannot be sustained, which is a result of the so-called prisoner's dilemma that firms find themselves caught within. The most important practical implication of the model is a call for external auditing with high assurance levels to ensure an efficient separation of highly and weakly sustainable firms.
\end{abstract}

Keywords: Sustainability Reporting, Game Theory, Signaling Theory, Prisoner's Dilemma JEL Classification: D52, D53, D82, M14, M49

\section{Introduction}

Several studies have raised the question of whether environmental and social disclosures are incrementally informative for capital market participants (e.g., Richardson and Welker, 2001; Plumlee et al., 2008; Clarkson et al., 2010). This question strictly relates to the issue of whether and how environmentally and socially responsible behavior is taken into account when making investment decisions and performing firm evaluations (Moskowitz, 1972, p. 71). This paper starts from the position that considering environmental, social, and economic issues simultaneously has a positive effect on shareholder value. It contributes to the literature by developing a comprehensive theoretical framework that describes conditions under which reporting on corporate sustainability is individually and collectively rational, and under which conditions it is probably not. The conclusion is made that firms might be caught in a prisoner's dilemma when sustainability reporting is collectively irrational and highly sustainable firms are forced to maintain sustainability reporting at a high level even though they would prefer to abandon sustainability reporting altogether.

*Email address: thomas.kaspereit@uni-oldenburg.de 
The remainder of this paper is structured as follows. Section 2 briefly describes the effects of corporate sustainability on the market value of firms. Section 3 applies the signaling theory to sustainability reporting. Section 4 analyzes whether a collectively preferred pooling equilibrium can be sustained from a signaling game theory perspective. Section 5 concludes and raises some issues for further research.

\section{The Effect of Corporate Sustainability on the Market Value of Firms}

The literature on the effects of corporate sustainability on firm value has become extensive in recent years (e. g., Dowell et al., 2000; Godfrey, 2005; Godfrey et al., 2009; Sharfman and Fernando, 2008). However, the lines of argument that can be found are similar: If it is assumed that management acts rationally and mainly on the behalf of shareholders, introducing corporate sustainability is either supposed to enhance expected cash flows, reduce investment risk, or both. This enhancement of future cash flows can result from a correlation between sustainability and efficiency of production processes as well as cost savings effects with regard to waste disposal, environmental charges, or recruitment (Klassen and McLaughlin, 1993, 1996; Lo and Sheu, 2007). It is also conceivable that corporate sustainability reduces expected cash flows due to higher expenditures for new factories or other implementation costs, but that this is outweighed by the reduction of the cost of capital, and the net effect on firm value is positive. The reduction of the cost of capital can be attributed to generating positive moral capital among communities and stakeholders, which can serve as an insurance-like protection for a firm's relationship-based intangible assets, and in turn reduce its exposure to stakeholder risks (Godfrey, 2005). From this perspective, corporate sustainability can be regarded as a tool to manage environmental, social, and economic risks.

Empirical results about the effects of corporate sustainability on expected cash flows, the cost of capital, or their aggregate market value are mixed, but generally indicate that in recent years corporate social and environmental performance has indeed been positively related to financial performance and market value (Orlitzky et al., 2003; Brammer and Pavelin, 2006; Bird et al., 2007; Semenova et al., 2009).

The theoretical analysis here is based on the assumption that a positive effect of corporate sustainability on the market value of a firm would exist provided that the degree to which the principle of corporate sustainability is followed by an individual firm was fully observable by capital market participants. However, in reality, corporate sustainability is hard to measure, and for the majority of investors is not directly observable. Firms need to communicate their sustainable behavior if they wish to benefit from it in the form of increased shareholder value. Sustainability reporting is intended to be an instrument for signaling corporate sustainability. Whether it can in fact serve this purpose depends on some of its characteristics which will be described in detail below.

\section{Sustainability Reporting as a Signaling Instrument and the Definition of Informational Equilibria}

For the example of the labor market, Spence $(1973,1974)$ describes how the hiring of workers can be regarded as an investment done under uncertainty. The uncertainty exists with respect to the 
productivity of workers, which is not known to the employer at the time they are hired. Here, the employer has to make an estimate about this characteristic. Only after some time can this estimate be confirmed or disproved. To influence the estimate of the employer, a worker can signal his abilities and productivity through education. The same framework can be applied to firms and with respect to their level of corporate sustainability. Capital market participants do not know the true level of corporate sustainability when they invest in a certain firm. Only after some time will they observe whether the firm's cash flow and risk profile are consistent with a stakeholder- and environment-oriented organizational structure. However, firms can attempt to signal their corporate sustainability to capital market participants through sustainability reporting. They can even feign a degree of sustainability that is different from what they actually do. Whether this strategy pays off in the short run depends on whether capital market participants consider the signal to be reliable, and in the long run whether this belief is confirmed by reality. What is required is an equilibrium of self-confirming beliefs. Self-confirming here means that the incentives for the firms arising out of the beliefs of the capital market participants make the company act in a way that confirms these beliefs. If, for instance, capital market participants more greatly value firms that report a high level of sustainability, this increase must outweigh the costs of reporting for highly but not for weakly sustainable firms. If weakly sustainable firms also have an incentive to report a high level of sustainability, the expectations of the capital market participants will be disproved and require adjustment.

\subsection{Properties of Separating Equilibria}

In order to describe the properties of equilibria in which sustainability reporting is sufficient for distinguishing highly from weakly sustainable firms, the population of firms is assumed to be nearly homogeneous, i. e., all firms are identical in every aspect except the degree to which they follow corporate sustainability and their cost-benefit structure with respect to sustainability. Corporate sustainability might be observed by employees, clients, and other closely related stakeholders (e. g., people living in the neighborhood of production plants), although it is impossible for capital market participants to screen all of their potential investment opportunities for sustainable behavior. Further, it is assumed that the population of firms is divided into weak and high sustainability, i. e., only two categories. The proportion of firms that follow a high degree of sustainability is $\lambda_{h}$, and the proportion of firms with a low degree of sustainability $\lambda_{l}$.

Two important functions have to be defined. The first describes the effect of corporate sustainability on the market value of the firm before the costs of reporting are considered. Since the true level of corporate sustainability is not directly observable by capital market participants, this function $\Delta$ is a function of the reported level of corporate sustainability $D$ rather than the true level:

$$
\Delta=\Delta(D)
$$

The specific characteristics of $\Delta(D)$ are not well known. Theoretically, even its first derivative could be both positive or negative. This results from the unanswered question of whether the benefits of sustainability outweigh its costs on the corporate level. In addition, it is not even known whether capital market participants expect firms with a higher reported level of corporate sustainability to be more sustainable. Setting these problems aside for a moment, it can be noticed that the reported 
level $D$ of corporate sustainability is under the discretion of management. Management decisions will be influenced by the true level of corporate sustainability $\theta$ if the costs of reporting depend on it. Consequently, the second important function to be defined is the cost function $C$ of reporting a certain level $D$ of corporate sustainability:

$$
C=C(a(\theta), D)=a(\theta) \cdot D
$$

It needs to be emphasized that $C$ only refers to the direct costs of reporting. These are the costs for issuing a sustainability report and, if a higher degree of sustainability is reported than actually followed, the expenses for so-called "greenwashing" (e.g., organizing charity events and their exploitation by marketing). It does not include other costs relating to real sustainable behavior and processes. Through this function, the costs of sustainability reporting are defined as the product of the reported level $D$ and a factor $a$. This factor itself is assumed to be a function of the true level of corporate sustainability. Spence (1973, pp.358-359) makes the crucial assumption that the costs of signaling are negatively correlated with the true level as he implicitly defines $a(\theta)=1 / \theta$ (Hindriks and Myles, 2006, p. 271). In this way, a higher positive level of true corporate sustainability would always lead to lower costs of reporting a certain degree of corporate sustainability. An infinite number of other functions that serve these conditions exists, such as the inverse sigmoid function $a(\theta)=e^{-\theta} /\left(1+e^{-\theta}\right)$ or the simple quadratic function $a(\theta)=\theta^{-2}$. Which function best proxies the true relationship between the costs of sustainability reporting and real corporate sustainability is an empirical question.

According to the assumption of rationality, firms maximize their total increase in shareholder value when they choose between different disclosure levels. Their decision problem can be expressed as

$$
\max _{\{D\}} \Delta(D)-a(\theta) \cdot D
$$

where the costs of reporting are measured as the present value of the cash flows resulting from the expenses of reporting.

Sustainability reporting is only an efficient instrument of capital market communication if it reliably separates highly sustainable from weakly sustainable firms. So the solution to the maximization problem (3) requires a higher reported level of sustainability for highly sustainable firms than for weakly sustainable firms. This is ensured when the net gains in shareholder value for highly sustainable firms are higher if they disclose a high level of corporate sustainability rather than report a low level; for weakly sustainable firms the net gains in shareholder value need to be smaller if they choose to disclose a high level of corporate sustainability compared to the case that they report a low level. With $D_{h}\left(D_{l}\right)$ indicating a high (low) reported level of corporate sustainability and $a_{h}\left(a_{l}\right)$ indicating the cost coefficient for highly (weakly) sustainable firms, this translates into the mathematical expressions

$$
\begin{array}{r}
\Delta\left(D_{h}\right)-a_{h}\left(\theta_{h}\right) \cdot D_{h}>\Delta\left(D_{l}\right)-a_{h}\left(\theta_{h}\right) \cdot D_{l} \\
\Delta\left(D_{l}\right)-a_{l}\left(\theta_{l}\right) \cdot D_{l}>\Delta\left(D_{h}\right)-a_{l}\left(\theta_{l}\right) \cdot D_{h} .
\end{array}
$$

If Conditions (4a) and (4b) are fulfilled, sustainability reporting manages to separate highly 
sustainable from weakly sustainable firms. For the weakly sustainable firms, there is no point in making any efforts to appear sustainable at all. This results from the fact that capital market participants immediately realize that a firm is of low corporate sustainability if it reports a lower level than $D_{h}$. Hence, in such a separating equilibrium $D_{l}$ will be zero. Then conditions (4a) and (4b) provide the lower and upper boundary of the reported level of corporate sustainability for the highly sustainable firms:

$$
\frac{\Delta\left(D_{h}\right)-\Delta\left(D_{l}\right)}{a_{l}\left(\theta_{l}\right)}<D_{h}<\frac{\Delta\left(D_{h}\right)-\Delta\left(D_{l}\right)}{a_{h}\left(\theta_{h}\right)} .
$$

Since reporting a higher level of sustainability is assumed to be more costly, and in the model only two different levels of corporate sustainability exist, there is no incentive for highly sustainable firms to report a higher level of corporate sustainability than the minimum to ensure that they are distinguished from the low level firms. Thus, they will report a level of corporate sustainability that is marginally higher than that expressed by the left-hand side of Inequation (5). This inequation further shows that, if the marginal costs of reporting as well as the effect of reporting on shareholder value differ, there will always be a level of sustainability reporting that ensures separation of the highly from the weakly sustainable firms. Therefore, different marginal costs of reporting and different effects of reported levels of sustainability on shareholder value are sufficient conditions for the existence of a reporting level $D_{h}$ that ensures separation.

\subsection{Violation of the Critical Assumptions}

If the assumption of different marginal costs of reporting or the assumption of variable effects of reported sustainability on shareholder value does not hold, the firms will end up in a pooling equilibrium in which no effort is spent on sustainability reporting. The proof is quite simple: If the marginal costs of reporting do not differ, no $D_{h}$ exists that satisfies Inequation (5). Both highly and weakly sustainable firms see the opportunity to gain an increase in shareholder value of $\Delta\left(D_{h}\right)$ if they report a higher level of sustainability than the others. Since the incentives do not differ between the groups, in the first round they will report up to the level at which the costs of reporting equal the positive effect of being seen as highly sustainable. Hence, equal marginal costs of reporting and competition between both groups make sustainability reporting an instrument that has neither a value for the individual firm, nor one that can serve as a signal to separate the highly from the weakly sustainable firms. In the second round, capital market participants will anticipate that sustainability reporting has no information value and disregard it when making their investment decisions. Therefore, in the third round no firm has an incentive to report on sustainability at all. Only then can an equilibrium with self-confirming beliefs be reached.

Constant effects of reported sustainability on shareholder value imply that capital market participants do not value corporate sustainability or sustainability reporting from the very start. This leads to the same outcome as no difference in the marginal costs of reporting, although here it is even more direct. When firms see that their effort in sustainability reporting will not be rewarded, there is no incentive to spend any effort in doing it, and firms will renounce the use of this instrument in general. 


\subsection{Properties of Pooling Equilibria}

As shown above, a lack of divergence in the marginal reporting costs leads to a pooling equilibrium in which sustainability reporting is of no use. Since by assumption sustainability reporting is the only potential signaling instrument, in such an equilibrium capital market participants cannot distinguish between highly and weakly sustainable firms. Therefore, if the proportions of both groups are known or at least can be estimated accurately, every firm will gain an average increase in shareholder value of $\lambda_{h} \cdot \Delta\left(\theta_{h}\right)+\lambda_{l} \cdot \Delta\left(\theta_{l}\right)$. Note here that the increase in shareholder value depends on the true level of corporate sustainability rather than the degree with which sustainability is reported.

Even when none of the critical assumptions is violated, the pooling equilibrium might be preferable for both highly and weakly sustainable firms. That is true if the average increase in shareholder value exceeds the increase in shareholder value highly sustainable companies would gain in a separating equilibrium:

$$
\lambda_{h} \cdot \Delta\left(\theta_{h}\right)+\lambda_{l} \cdot \Delta\left(\theta_{l}\right)>\Delta\left(D_{h}\right)-a_{h}\left(\theta_{h}\right) \cdot D_{h}
$$

The value of $D_{h}$ is determined from the left-hand side of Inequation (5), whereby the reported level of sustainability is set to the only rational level of zero for weakly sustainable firms. Thus, it follows

$$
\lambda_{h} \cdot \Delta\left(\theta_{h}\right)+\lambda_{l} \cdot \Delta\left(\theta_{l}\right)>\Delta\left(D_{h}\right)-a_{h}\left(\theta_{h}\right) \cdot \frac{\Delta\left(D_{h}\right)-\Delta\left(\theta_{l}\right)}{a_{l}\left(\theta_{l}\right)} .
$$

Knowing that $\lambda_{l}=1-\lambda_{h}$ as well as that in a separating equilibrium only highly sustainable firms report a high level of sustainability $\left[\Delta\left(D_{h}\right)=\Delta\left(\theta_{h}\right) ; \Delta\left(D_{l}\right)=\Delta\left(\theta_{l}\right)\right]$, rearranging leads to

$$
\lambda_{h}>1-\frac{a_{h}\left(\theta_{h}\right)}{a_{l}\left(\theta_{l}\right)} \Leftrightarrow \lambda_{l}<\frac{a_{h}\left(\theta_{h}\right)}{a_{l}\left(\theta_{l}\right)} .
$$

Inequation (8) shows that a pooling equilibrium with no signaling is preferred if the highly sustainable firms are a majority, where majority is defined as a proportion exceeding $1-a_{h}\left(\theta_{h}\right) / a_{l}\left(\theta_{l}\right)$. The inequation spans a surface boundary in the three-dimensional space that divides the vectors $\left(\lambda_{h}, \theta_{h}, \theta_{l}\right)$ in those of preferred pooling (above) and separating equilibria (below). Figure 1 shows this for cases of $a(\theta)=1 / \theta$ and $a(\theta)=e^{-\theta} /\left(1+e^{-\theta}\right)$.

Whether a pooling or separating equilibrium is preferred depends on the concrete values of the parameters $\lambda_{h}, \theta_{h}$, and $\theta_{l}$. They indicate to a point above the surface boundary if the true levels of corporate sustainability do not greatly differ, the costs of sustainability reporting are not very sensitive to the true level of corporate sustainability, and/or when the proportion of highly sustainable firms is relatively large. If the cost functions of sustainability do not differ at all, the surface boundary would be a hyperplane at the bottom of the three-dimensional space. Here, pooling would always be preferred.

\section{Sustainability Reporting as a Signaling Game when Pooling is Collectively Preferred}

The analysis so far has shown that under certain circumstances both highly and weakly sustainable firms would prefer to abstain from any sustainability reporting rather than enforce a separating 


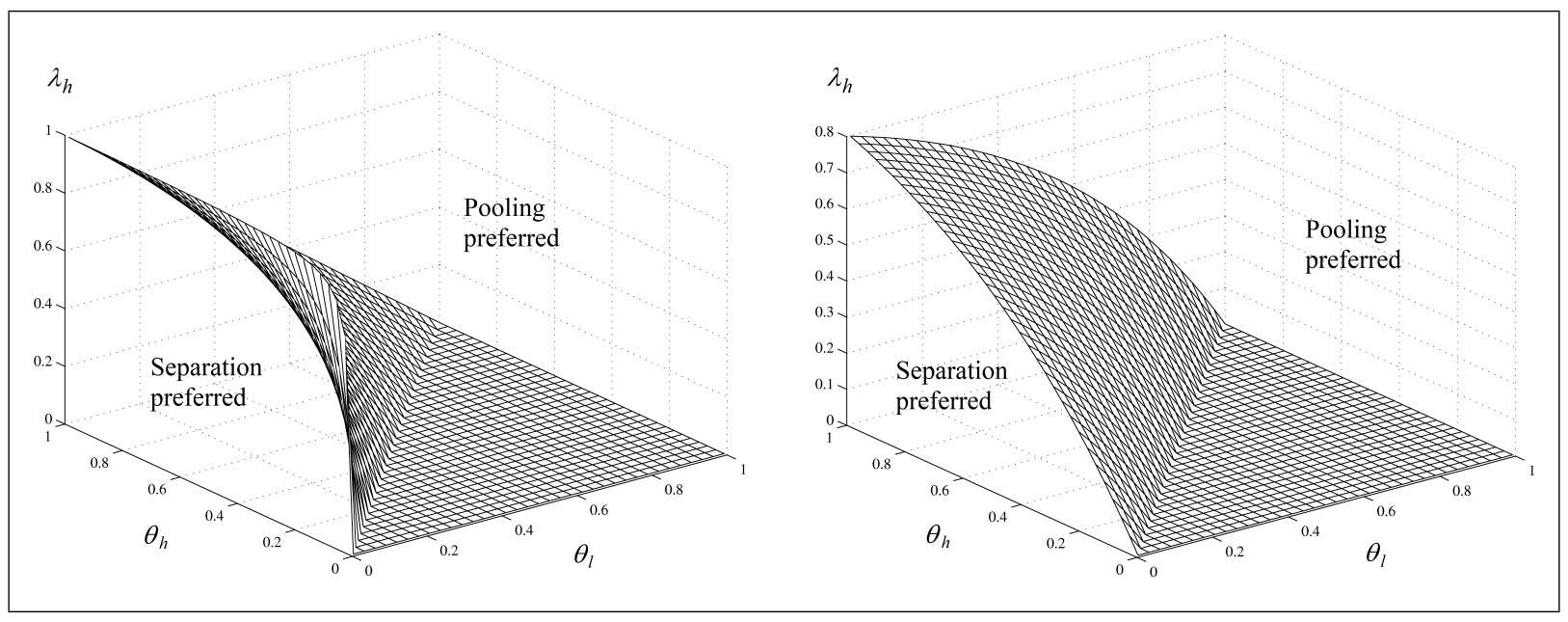

Figure 1. Preferences for Separating and Pooling Equilibria when Costs of Sustainability Reporting are Proportional to the Inverse of True Corporate Sustainability (Left-hand Side) and Determined by an Inverse Sigmoid Function (Right-hand Side).

equilibrium. Now the question arises of whether a pooling equilibrium of no sustainability reporting is actually sustainable. Even though a pooling equilibrium might be collectively preferable, it may also be individually rational to deviate from it.

To predict how firms act when pooling is collectively preferred, sustainability reporting will be modeled below as a game between the two blocks of highly and weakly sustainable firms. The standard procedure to predict the outcome of such games is to search for strategic choices that are stable, i. e., no party can be better off by unilaterally changing its strategy (Kohlberg and Mertens, 1986, p. 1003). As Nash (1951, p. 286) points out, pairs of opposing "good [reporting] strategies" are sought here. In the framework of sustainability reporting, the strategies are the reported levels of sustainability $D_{i}$ and $D_{-i}$. The subscripts $i$ and $-i$ indicate the different blocks of firms. A so-called Nash equilibrium is then defined as

$$
\Delta_{i}\left(D_{i}^{*}, D_{-i}\right) \geq \Delta_{i}\left(D_{i}^{\prime}, D_{-i}\right) \quad \forall D_{i}^{\prime}, \forall i
$$

Every strategy $D_{-i}$ can be answered by the other party in three ways: reporting the same level of sustainability, deviating to a higher level, or deviating to a lower level. When deviating to a higher level is chosen, only a marginal deviation can be rational since this ensures that the increase in shareholder value is $\Delta\left(D_{h}\right)$ instead of the pooling value, while costs are minimized. Deviating to a lower level can only be rational if the zero level is chosen because the zero level is the cost-optimal alternative of all reporting levels that result in a change in shareholder value of $\Delta\left(D_{l}\right)$.

From the perspective of the firms, it is rational to deviate to a marginally higher level $D_{i}=$ $D_{-i}+d D$ if the net gain from winning $\Delta\left(D_{h}\right)-\Delta\left(D_{l}\right)$ exceeds the costs of reporting, $a_{i}\left(\theta_{i}\right) \cdot D_{i}$. Therefore, $D_{i}=D_{-i}+d D$ is the best response to strategy $D_{-i}$ as long as

$$
D_{i}<\frac{\Delta\left(D_{h}\right)-\Delta\left(D_{l}\right)}{a_{i}\left(\theta_{i}\right)}
$$


If $D_{-i}$ equals or exceeds the right-hand side of Inequation (10), deviation to the zero level is the best response. If $D_{-i}$ is lower, it is always possible to find a value of $D_{i}$ that is also lower than the right-hand side of Inequation (10) but marginally higher than $D_{-i}$. As can already be seen, reporting the same level of corporate sustainability is never a best response to any other strategy. The reaction function is given by

$$
D_{i}\left(D_{-i}\right)= \begin{cases}D_{-i}+d D & \text { for } D_{-i}<\frac{\Delta\left(D_{h}\right)-\Delta\left(D_{l}\right)}{a_{i}\left(\theta_{i}\right)} \\ 0 & \text { for } D_{-i} \geq \frac{\Delta\left(D_{h}\right)-\Delta\left(D_{l}\right)}{a_{i}\left(\theta_{i}\right)} .\end{cases}
$$

The left-hand side of Figure 2 shows the reaction functions of both parties when the cost coefficient $a_{i}$ is half as high for the highly sustainable firms than for the weakly sustainable firms. The functions are discontinuous at the critical levels of reported sustainability as defined by Inequations (10) and (11) and consequently do not cross.

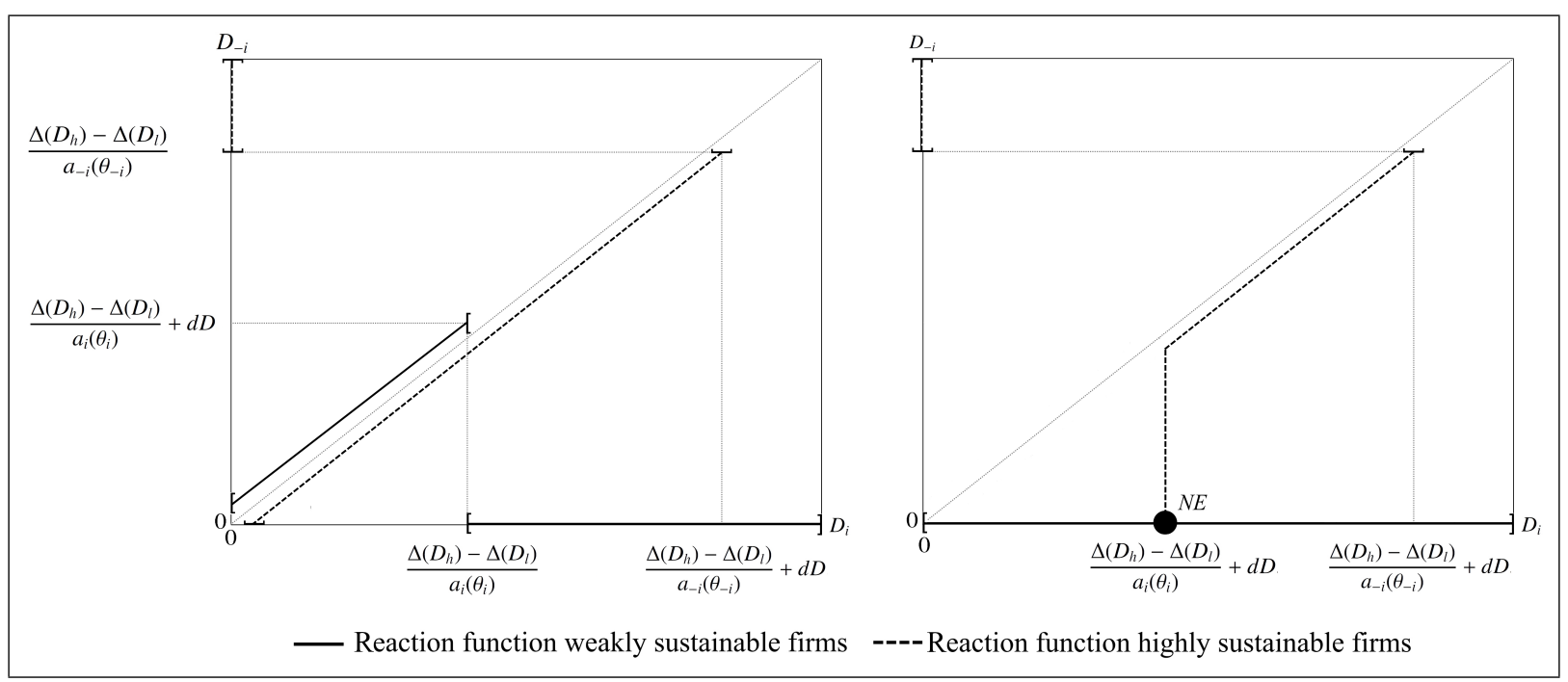

Figure 2. Reaction Functions of Weakly and Highly Sustainable Firms Showing the Best Response to Each Other's Reported Level of Sustainability (Left-hand Side) in a Multi-period Framework with High Costs of Changing the Reported Level of Sustainability (Right-hand Side).

Hence, no combination of $D_{i}$ and $D_{-i}$ can be found that satisfies condition (9), and no Nash equilibrium exists. The consequences of this insight are profound. Standard game theory does not provide an answer regarding which level of reported sustainability the firms are supposed to choose. The solution to this problem could be setting up a multi-period framework in which one party is selected as the beginner and the other as the follower. Here the follower could give a best response to the decision of the beginner. In the next period the beginner reacts with his response and so on. It can easily be seen that this would end up in cyclical behavior: In the interval from zero to $D_{i}=\frac{\Delta\left(D_{h}\right)-\Delta\left(D_{l}\right)}{a_{i}\left(\theta_{i}\right)}$, the firms overbid each other until the highly sustainable firms marginally cross the border, and the weakly sustainable firms fall back to the zero reporting level. In the next round, the best response for the highly sustainable firms is reducing their reported level to a value marginally above zero, and the cycle begins again. 
Such behavior is in reality not observable, at least not in the short run. Firms do not permanently change their corporate sustainability strategy in response to the strategies of others. Choosing a certain level of corporate sustainability and sustainability reporting is a strategic decision that cannot be altered continuously. After all, this would result in additional costs due to the perpetual changes and a decline in the company's credibility resulting from their permanently altering signals they were sending. These costs are not considered in the basic model. If the costs of altering the reported level of sustainability are considerably high and outweigh any gains in shareholder value, the firms will choose a level of reported sustainability that ensures that in the following rounds no change has to be made because the other party would overbid the own level. Here, the best response is the one with respect to all of the following rounds. The only levels that fulfill this condition are $D_{i}>\frac{\Delta\left(D_{h}\right)-\Delta\left(D_{l}\right)}{a_{i}\left(\theta_{i}\right)}$ for the highly sustainable firms and $D_{-i}=0$ for the weakly sustainable firms. The multi-period reaction functions are then shaped as shown in the right hand side of Figure 2 . The only point of intersection lies at $D_{i}=\frac{\Delta\left(D_{h}\right)-\Delta\left(D_{l}\right)}{a_{i}\left(\theta_{i}\right)}+d D ; D_{-i}=0$ and depicts the Nash equilibrium $(N E)$ that satisfies condition (9). Hence, even if a pooling equilibrium is Pareto-dominating, the only equilibrium outcome is a separating equilibrium in which the highly sustainable firms report a level of sustainability that barely forces the weakly sustainable firms to abstain from sustainability reporting. Thus, in this case weakly and highly sustainable firms are caught in a situation that is referred to as a (multi-period) prisoner's dilemma (Tucker, 1950, pp. 7-8). The individually rational behavior leads to a collectively inefficient outcome.

\section{Conclusion}

The analysis of corporate sustainability reporting from a game theory perspective leads to three conclusions:

1. If the critical assumptions of differing reporting costs for different levels of true corporate sustainability hold, there is always a level of reported sustainability that ensures a separation of the highly from the weakly sustainable firms.

2. If the highly sustainable firms are a majority and/or the advantages in the costs of sustainability reporting of the highly sustainable firms are relatively small (i.e., condition (8) holds), both highly and weakly sustainable firms would prefer to abstain from sustainability reporting and set up a pooling equilibrium instead.

3. A pooling equilibrium can only be sustained if the critical assumption of differing costs does not hold. Otherwise the outcome of the game is always a Pareto-dominated separating equilibrium (prisoner's dilemma).

Therefore, the predicted outcome of the analytical model depends on the specific values of its parameters. These values can be determined by observing the actual business world and further empirical studies. Intuition can also provide some hints. If the degree of sustainability is overstated, issuing sustainability reports might be slightly but not much costlier due to the measures that may need to be taken to maintain the facade. Furthermore, the amount of firms discovering the potentials of corporate sustainability appear to be on the continual rise along with the amount of sustainability reports that are being issued (see Kolk, 2003; Jose and Lee, 2006; Barkemeyer et al., 2009). Thus, intuition indeed suggests that competition between highly and weakly sustainable firms enforces a 
separating equilibrium even though both would prefer the pooling solution, and both highly and weakly sustainable firms are caught in a prisoner's dilemma. This outcome of the model calls for measures that increase the reliability of sustainability reports, for instance external auditing with high assurance levels. High assurance levels have the potential to increase the difference between the cost coefficients of highly and weakly sustainable firms, and in doing so might increase the likelihood of an efficient separating equilibrium.

The analysis conducted here very obviously has some limitations. First of all, the assumption that only two kinds of firms exist is not realistic. Various degrees and dimensions of true sustainability exist, and every one of them may be rewarded by the capital market in a different way. In reality, there is an $n$-firm game rather than a two-party setup. In addition, true corporate sustainability was considered in this paper to be a constant, even though companies can choose their true levels, at least in the long run. Consequently, not only the reported level is subject to the game theory analysis, but the true level of corporate sustainability as well. The most important limitation of the analysis seems to be the assumption that firms will gain the average increase in shareholder value if both parties report the same level and do not differ from each other in their reporting practices. This implies that capital market participants have knowledge about the true proportions of highly and weakly sustainable firms in the population. The question thus arises from where this knowledge might result when no effective reporting about corporate sustainability exists. The answers to this question are sparse indeed, so the most promising one is experience from the past: Capital market participants can learn from former investments what impact exposure of their firms had on economic, environmental, and social risks.

Further analytical research can aim at mitigating some of the limitations mentioned above. Nevertheless, even more interesting would be the search for answers to the empirical questions that have emerged. How do the costs of sustainability reporting relate to the true level of sustainability? And would it indeed be preferable for firms to abstain from sustainability reporting and implement more reliable instruments for signaling true corporate sustainability? The possible methodical approaches to answer these questions vary greatly. Content analysis provides the opportunity to measure the reported level of sustainability, while in-depth sustainability rankings from certain agencies deliver proxies for the true levels, and can even serve as explanatory variables.

\section{References}

Barkemeyer, R., Figge, F., Holt, D., Hahn, T., 2009. What the papers say: Trends in sustainability. Journal of Corporate Citizenship (33), 69-86.

Bird, R., Hall, A. D., Momentè, F., Reggiani, F., 2007. What corporate social responsibility activities are valued by the market? Journal of Business Ethics 76 (2), 189-206.

Brammer, S. J., Pavelin, S., 2006. Corporate reputation and social performance: The importance of fit. Journal of Management Studies 43 (3), 435-455.

Clarkson, P., Fang, X. H., Li, Y., Richardson, G., 2010. The relevance of environmental disclosures for investors and other stakeholder groups: Are such disclosures incrementally informative? Accessed 08-05-2011. URL http://papers.ssrn.com/sol3/papers.cfm?abstract_id=1687475

Dowell, G., Hart, S., Yeung, B., 2000. Do corporate global environmental standards create or destroy market value? Management Science 46 (8), 1059-1074.

Godfrey, P. C., 2005. The relationship between corporate philanthropy and shareholder wealth: A risk management perspective. Academy of Management Review 30 (4), 777-798. 
Godfrey, P. C., Merrill, C. B., Hansen, J. M., 2009. The relationship between corporate social responsibility and shareholder value: An empirical test of the risk management hypothesis. Strategic Management Journal 30 (4), 425-445.

Hindriks, J. J. G., Myles, G. D., 2006. Intermediate Public Economics. MIT Press, Cambridge, Mass.

Jose, A., Lee, S.-M., 2006. Environmental reporting of global corporations: A content analysis based on website disclosures. Journal of Business Ethics 72 (4), 307-321.

Klassen, R. D., McLaughlin, C. P., 1993. TQM and environmental excellence in manufacturing. Industrial Management \& Data Systems 93 (6), 14-22.

Klassen, R. D., McLaughlin, C. P., 1996. The impact of environmental management on firm performance. Management Science 42 (8), 1199-1214.

Kohlberg, E., Mertens, J.-F., 1986. On the strategic stability of equilibria. Econometrica 54 (5), 1003-1037.

Kolk, A., 2003. Trends in sustainability reporting by Fortune Global 250. Business Strategy and the Environment 12 (5), 279-291.

Lo, S.-F., Sheu, H.-J., 2007. Is corporate sustainability a value increasing strategy for business? Corporate Governance: An International Review 15 (2), 345-358.

Moskowitz, M. R., 1972. Choosing socially responsible stocks. Business and Society Review 1 (1), 71-75.

Nash, J., 1951. Non-cooperative games. Annals of Mathematics 54 (2), 286-295.

Orlitzky, M., Schmidt, F. L., Rynes, S. L., 2003. Corporate social and financial performance: A meta-analysis. Organization Studies 24 (3), 403-441.

Plumlee, M., Brown, D., Marshall, S., 2008. The impact of voluntary environmental disclosure quality on firm value. Accessed 08-01-2010.

URL http://papers.ssrn.com/sol3/papers.cfm?abstract_id=1140221\#

Richardson, A. J., Welker, M., 2001. Social disclosure, financial disclosure and the cost of equity capital. Accounting, Organizations and Society 26 (7/8), 597-616.

Semenova, N., Hassel, L. G., Nilsson, H., 2009. The value relevance of environmental and social performance: Evidence from Swedish SIX 300 companies. Accessed 08-12-20110.

URL http: //www.pwc.com/sv_SE/se/hallbar-utveckling/assets/sammanfattning_six300.pdf

Sharfman, M. P., Fernando, C. S., 2008. Environmental risk management and the cost of capital. Strategic Management Journal 29 (6), 569-592.

Spence, A. M., 1973. Job market signaling. Quarterly Journal of Economics 87 (3), 355-374.

Spence, A. M., 1974. Market Signaling: Informational Transfer in Hiring and Related Screening Processes. Vol. 143 of Harvard Economic Studies. Harvard University Press, Cambridge, Massachusetts.

Tucker, A. W., 1950. A two-person dilemma (unpublished notes from Stanford University). In: Rasmusen, E. (Ed.), Readings in Games and Information (2001). Blackwell, Boston, pp. 7-8. 